\title{
Indiscriminate ossification of ligaments in a dry adult human male pelvis- A rarity
}

\author{
Amit Tirpude ${ }^{1, *}$, PraKash Mishra ${ }^{2}$, Manisha Gaikwad ${ }^{3}$, Praveen K. Ravi ${ }^{4}$, Mantu Jain ${ }^{5}$ \\ ${ }^{1,5}$ Assistant Professor, ${ }^{2,3}$ Additional Professor, ${ }^{4}$ Junior Resident, ${ }^{\mathbf{1 2 , 3 , 4}}$ Dept. of Anatomy, ${ }^{\mathbf{5}}$ Dept. of Orthopedics, All India Institute \\ of Medical Sciences, Bhubaneswar, Odisha, India \\ *Corresponding Author: \\ Email: amit_tirpude2005@rediffmail.com
}

Received: $9^{\text {th }}$ February, 2018

Accepted: $22^{\text {nd }}$ February, 2018

\begin{abstract}
Introduction: Human pelvis exhibits sacrotuberous, sacrospinous and transverse acetabular ligament performing the function of stabilisation of pelvis and hip joint respectively. The ossification of this ligaments has been reported solitary and rarely in composite.

Materials and Methods: During undergraduate osteology teaching authors noticed a dry human male pelvis demonstrating compounded ossification of ligaments and bony distortions.

Case Report: The left sacrotuberous ligament was partially ossified and demonstrated triangular anteroinferior and posterosuperior segments. The transverse acetabular ligament of right side was totally ossified and left was partially ossified. A bony mass was observed at the left ala of sacrum with fusion of pedicle and left lower part of body of fifth lumbar vertebra and ala of sacrum. Bilateral sharp bony spicules at iliopectineal lines and exostosis at bilateral iliac tuberosity was noticed.

Conclusion: This exhibit brings out an unreported rare anatomical variant of bony pelvis, the knowledge of which will be of paramount importance to radiologists and orthopaedic surgeons.
\end{abstract}

Keywords: Sacrotuberous ligament, Transverse acetabular ligament, Ossification, Sacralisation, Bony spicule.

\section{Introduction}

Human bony pelvis is a bridge transmitting the weight from lower extremity to axial skeleton which is aided by the sacrotuberous, sacrospinous and transverse acetabular ligaments. These ligaments are tough, flexible and pliant fibrous band connecting bones, but also create foramina's allowing passage to Neuro-vascular structures and attachments to muscles. The Sacrotuberous ligament (STL) is a connection between the sacrum and the ischial tuberosity. It is hour glass shaped narrow in middle and expanded at both ends. At one end it is attached to the posterior superior iliac spine, adjoining ligaments, transverse sacral tubercles and the lateral margins of the lower sacrum and upper coccyx; while the other end to the medial margin of the ischial tuberosity. The Sacrospinous ligament (SSL) extends from ischial spine to the sacrum. The two ends of the acetabular notch give attachment to the transverse acetabular ligament. ${ }^{1}$ STL stabilizes the pelvis and locking the sacroiliac joint, by counterbalancing its rotation, therefore limiting the movement of the lower portion of sacrum. ${ }^{2}$

Abnormal Osseo-tendinous behaviour in pelvic ligaments either calcification, ossification, bony outgrowths (enthesophytes and osteophytes) are solitarily reported in radiological and anatomical literature but data about soft tissue at pelvic brim is negligible. Ossification of STL, SSL \& TAL may compress associated Neuro-vascular vascular structures leading to perineal pain and limitations of hip movements.
Lumbosacral transitional vertebra (LSTV) is a common congenital anomaly of lumbosacral region which may include sacralisation and lumbarisation. Sacralisation is a congenital condition in which usually the fifth lumbar vertebra fuses completely or partially with sacrum unilaterally or bilaterally. The prevalence rate of LSTV varies from $4 \%$ to $35.9 \%$ based on diagnostic criteria, imaging techniques and on the clinical presentation of the patient. ${ }^{3}$ LSTV may pose neurological, disc related or midwifery situations.

Authors report a very rare presentation of ossified left sacrotuberous ligament, bilateral transverse acetabular ligaments, anterior longitudinal ligament with sacralisation of fifth lumbar vertebra and bony spurs at both iliopectineal lines in a human pelvis.

\section{Case Report}

During routine demonstration authors were attracted towards a male articulated pelvis. It was supplied by independent vendor to the institute and had some interesting features as described below. Digital Vernier calliper with a reading sensitivity of $0.01 \mathrm{~mm}$ was used to measure the dimensions.

1. The outlet showed partially ossified left sacrotuberous ligament (STL). It had a broad-based origin at the ischial tuberosity and exhibited a characteristic tapering end cranio-medially. It demonstrated characteristic spiralling along its longitudinal axis, which divided the ossified STL into triangular antero-inferior (AI) and slate pencil like postero-superior (PS) segments. From the 
prominent inner margin of ischial tuberosity to the tip the length of the ossified STL was $54.0 \mathrm{mms}$ with AI segment measuring $27.9 \mathrm{~mm}$ and PS measuring $26.1 \mathrm{~mm}$. The AI segment was continuous with ossified falciform process and had two surfaces where in its inferior surface was more irregular than the superior surface. The PS also exhibited two surfaces lateral and medial wherein the lateral surface was more irregular. The apex of this ossified STL threw multiple small bony protuberances with intervening groove. The contralateral STL was not ossified but the medial side of ischial tuberosity was very rough and marginally elevated continuous with ossified falciform process. The ischial spines were prominent (Fig. 1).

2. The inlet showed fifth lumbar vertebrae having a rounded bony mass encroaching the medial two third of left ala and forming a narrow tunnel along the medial aspect of the left sacroiliac joint. The mass was continuous with left lower part of body and pedicle of fifth lumbar vertebra (Fig. 2). The transverse process and articular facets of fifth and first sacral vertebra were separate. The uncal process, facets and the rim of body showed osteophytes. The anterior surface of body of vertebra showed ossified bony process of $22.7 \mathrm{~mm}$ in middle extending vertically from lower rim to cross upper rim. Authors conclude this as ossified anterior longitudinal ligament.

3. On pelvic brim authors noticed equimorphic bilateral bony spicules beginning medial to iliopubic eminence and ending with a sharp pointed end on pectinate line. Right and left bony spicule were $22.6 \mathrm{~mm}$ and $30.1 \mathrm{~mm}$ in length and were at 26.5 and $26.7 \mathrm{~mm}$ from medial end of pubic crest respectively (Fig. 2).

4. Coming to anterolateral portion of pelvis, both the transverse acetabular ligaments (TAL) were ossified. The right ligament was complete and left side was incomplete measuring $31.2 \mathrm{~mm}$ X $5.6 \mathrm{~mm}$ and $15.8 \mathrm{~mm} \mathrm{X} 4.9 \mathrm{~mm}$ (length $\mathrm{X}$ breadth) respectively (Fig. 3 and 4 ).

5. Both the iliac tubercles were more prominent than usual and showed beak like exostosis. The area above the acetabulum was more robust and showed tubercles. Authors assume this as a hint to attempt to ossify the ITT. The sacroiliac joints and sacral spines were normal (Fig. 1).

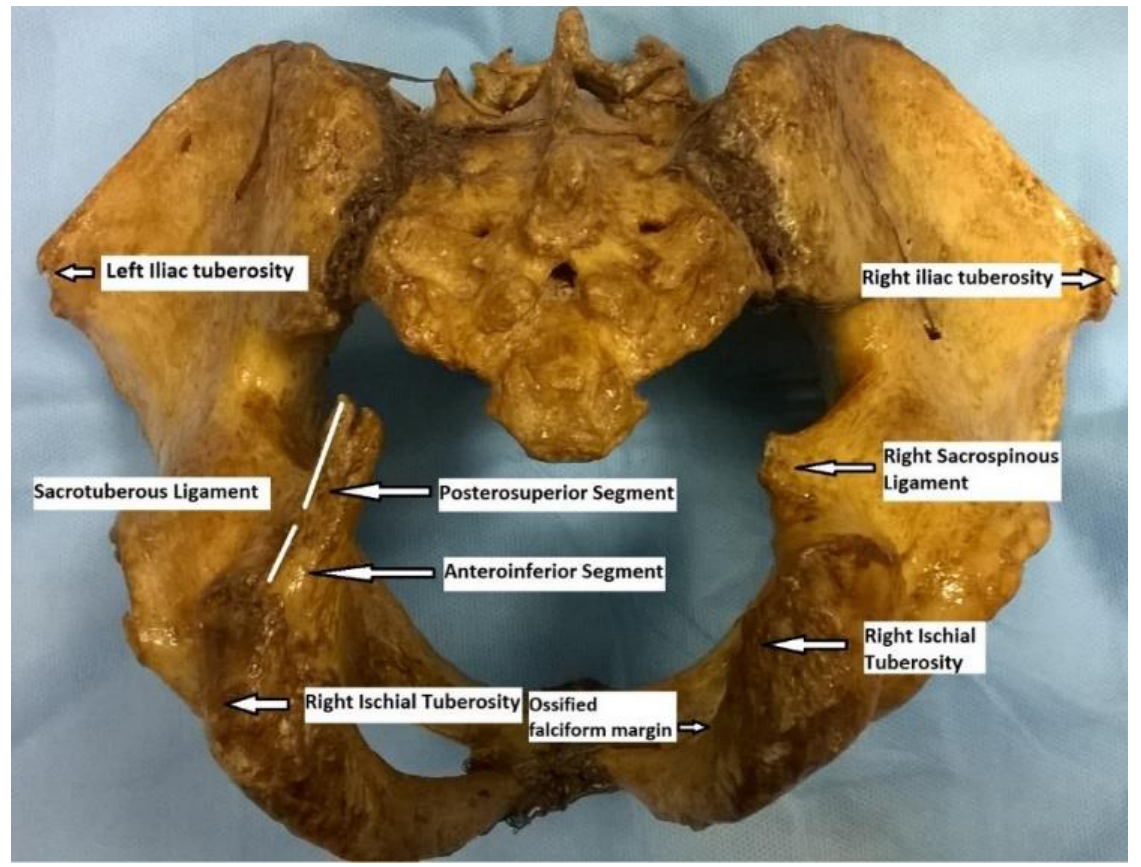

Fig. 1: Photograph of outlet of pelvis showing ossified left Sacrotuberous ligament, bilateral prominent iliac tuberosities and ossified right falciform margin of Sacrotuberous ligament 


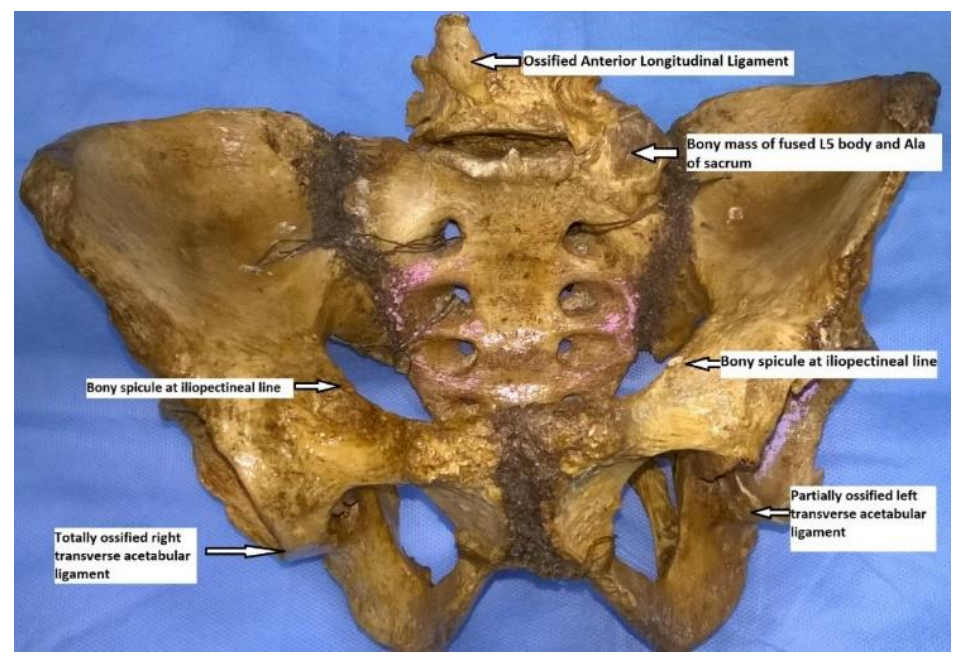

Fig. 2: Photograph of inlet of pelvis showing bilateral variant ossification of transverse acetabular ligaments, fusion of body of L5 vertebra with ala of sacrum and bilateral bony spicules at iliopectineal lines

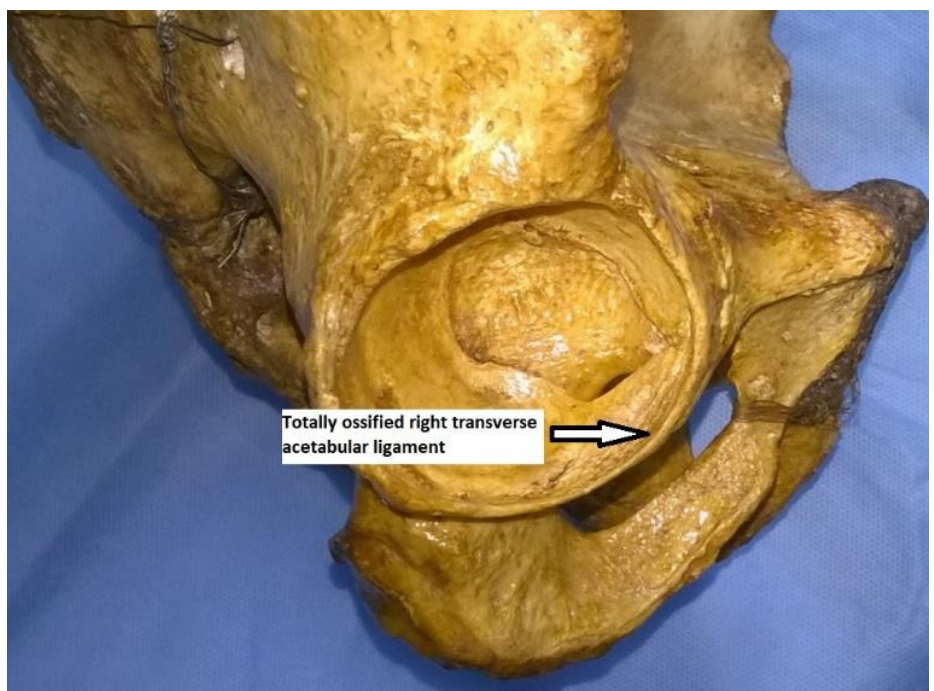

Fig. 3: Photograph of right anterolateral part of pelvis showing totally ossified right transverse acetabular ligament

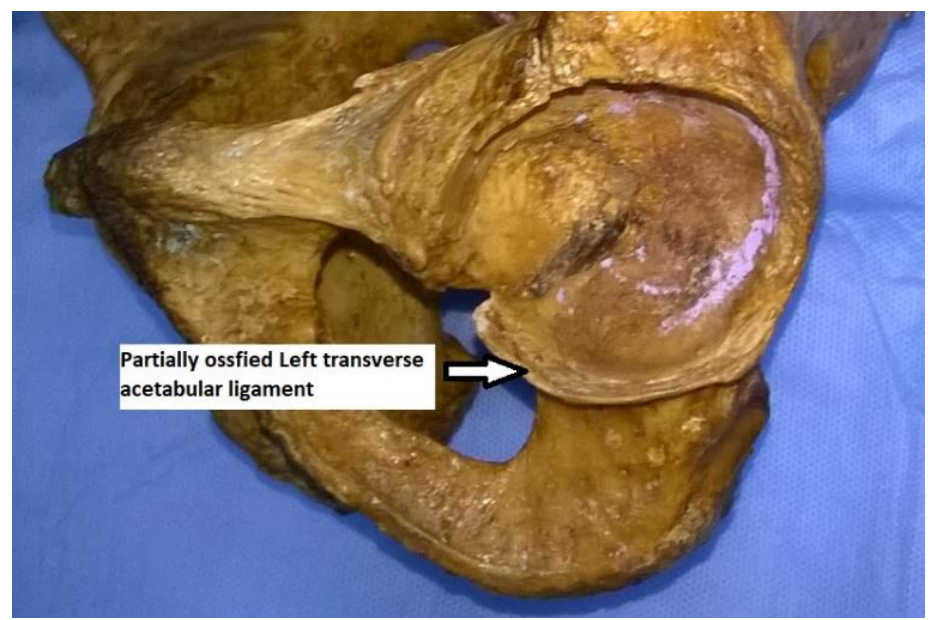

Fig.4. Photograph of left anterolateral part of pelvis showing partially ossified left transverse acetabular ligament 


\section{Discussion}

Calcification or ossification of STL is reported in radiological literature as a unilateral, ${ }^{4}$ incidental, ${ }^{4}$ acquired and not epigenetic. ${ }^{5}$ It is seen mostly in men ${ }^{6}$ and is inconclusive about occupational or special stress. ${ }^{7}$ Fibroblasts cells are present in large number in ligamentous tissue and are reported to be linked with heterotopic ossification in ligaments. However, the proper mechanism by which fibroblasts mediate this remains uncertain. Due to external stimulus like repetitive strain on these structures causes lifting of periosteum exposing the osteogenic layer containing osteocytes which in turn form the bony out growth. ${ }^{8}$ This may be indicative of spinal Diffuse Idiopathic Skeletal Hyperostosis (DISH) $)^{9,10}$ or any seronegative spondyloarthropathy. ${ }^{11}$

The pudendal nerve enters the pudendal canal which is formed by duplication of the obturator fascia, inferior to falciform process and insertion of STL into the ischial tuberosity. ${ }^{7}$ An ossified STL may act as a lobster claw and with a restricted anatomical space may compress the pudendal nerve clinically producing the entrapment syndrome causing chronic perineal pain or loss of sensation. ${ }^{12}$ It may also compress inferior gluteal artery branches and result in ischemia of area supplied. Ossified Sacrotuberous ligament may affect general stability of sacropelvic articulation. ${ }^{13}$ The falciform process extension has been classified whether it is continuous with obturator fascia only (type I) or also with anococcygeal ligament (type II) or process is absent (type III). ${ }^{14}$ This case of dry bone may mould into type I or II. In either there may need to be relieved by surgical sectioning of STL.

The ossified TAL limits the movement of hip joint and leads to the compression of the medial circumflex femoral vessels (nutrient vessel) and subsequently results in ischemia of the area supplied by it. TAL is an important landmark for cup placement and its ossification problems in registering bony landmarks during total hip arthroplasty. ${ }^{15}$

The primary cause of Lumbosacral transitional vertebra (LSVT) is cranial shift of caudally placed densely packed cells of sclerotome that means sacralization of last lumber vertebra and partial shift means unilateral fusion of transverse process. Caudal shift results in lumbarisation of the first sacral vertebra, but cranial shift is dominant over caudal shift. So sacralization is more common than lumbarisation. ${ }^{16}$ Sacralization of fifth lumbar vertebra may cause complication like pain due pressure on nerves and nerve trunk, strain in ligaments, disc herniation and difficult normal labour. Authors can't rule out possibility of tumour as mass of bone is uneven and large.

The Authors assume the enthesophytes at both the iliopectineal lines either as ossified cooper's pectineal ligament or iliopectineal arch. Clinically, the bony spurs may impinge on pectineus muscle causing spasm and pain during adduction of thigh. It may also damage the fibres of conjoint tendon which make the person susceptible to inguinal hernia. The femoral sheath and its content may also be damaged by the spur. ${ }^{17}$ The iliac tubercle presented the signs of initiation ossification of ITT which may lead to pain during walking, running and hip abduction.

Authors declare that neither demographic data nor medical history of this pelvis was available.

\section{Conclusion}

Authors like to aware the radiologist and orthopaedic surgeons about this compounded ossification effect in pelvic ligaments and soft tissue which may present with neurovascular symptoms and if unnoticed operative hazards.

Conflict of Interest: The Authors declare that there is no conflict of interest.

\section{References}

1. Standring S. Gray's anatomy: the anatomical basis of clinical practice. 41st ed. New York: Elsevier Churchill Livingstone, 2016, p.1339-47.

2. Moore K L, Dalley A F. Clinically oriented anatomy. 4th ed. Philadelphia: Lippincott Williams \& Wilkins, 1999, p.32738.

3. Vergauwen S, Parizel PM, Breusegem LV et al. Distribution and incidence of degenerative spine changes in patients with a lumbosacral transitional vertebra. Eur Spine J 1997;6:168-72.

4. Heuck FHW. Radiologie des gesunden Skeletts. In: Schinz HR, Baensch WE, Formmhold W, Glauner R, Uehlinger E, Wellauer J (eds) Lehrbuch der Röntgendiagnostik, vol 2/1. Thieme, Stuttgart.1979, pp.106.

5. Prescher A and Bohndorf K. Anatomical and radiological observations concerning ossification of the Sacrotuberous ligament: is there a relation to spinal diffuse idiopathic skeletal hyperostosis (DISH)?. Skeletal Radiol 1993;22:581-5.

6. Forestier J and Lagier R. Ankylosing hyperostosis of the spine. Clin Orthop Relat Res 1971;74:65-83.

7. Hough D. M, Wittenberg K. H, Pawlina W et al. Chronic perineal pain caused by pudendal nerve entrapment: anatomy and CT-guided perineural injection technique. AJR Am J Roentgenol 2003;181:561-7.

8. Scapinelli R, Stecco C, Pozzuoli A, et al. The lumbar interspinous ligaments in humans: anatomical study and review of the literature. Cells Tissues Organs 2006;183:111.

9. Haller J, Resnick D, Miller CW et al. Diffuse idiopathic skeletal hyperostosis: diagnostic significance of radiographic abnormalities of the pelvis. Radiology 1989; $172: 835$.

10. Resnick D, Shaul SR and Robins JM. Diffuse idiopathic skeletal hyperostosis (DISH). Forrestiers disease with extra spinal manifestations. Radiology. 1975;115:513-24.

11. Niepal GA and Sitaj S. Enthesopathy. Clin Rheum Dis. 1979; 5:857-72.

12. Robert R, Prat-Pradal D, Labat JJ et al. Anatomic basis of chronic perineal pain: role of the pudendal nerve. Surg Radiol Anat 1998;20:93-8. 
13. Beyth S, Liebergall M and Mosheiff R. Myositis ossificans circumscripta of the sacrotuberous ligament: a case report and review of the literature. J Orthop Trauma 2002;16:6724.

14. Loukas M, Louis RG Jr, Hallner B, et al. Anatomical and surgical considerations of the sacrotuberous ligament and its relevance in pudendal nerve entrapment syndrome. Surg Radiol Anat 2006;28:163-9.

15. Sam Hakki, Victor Bilotta, Janiel Oliveira et al. Acetabular Center Axis: Is It the Future of Hip Navigation?. Orthopaedics 2010;33:43-7.

16. Sharma V. A, Sharma D. K and Shukla C. K. Osteogenic study of Lumbosacral transitional vertebra in central India region. J. Anat. Soc. India 2011;60:212-7.

17. Singh Rajani. Bony spurs projecting in the obturator foramen. Folia Morphol 2012;71:125-7. 